\title{
MULHER E TRABALHO - A HISTÓRIA DE VIDA DE MÃES TRABALHADORAS DE ENFERMAGEM
}

Spindola T, Santos RS. Mulher e trabalho - a história de vida de mães trabalhadoras de enfermagem. Rev Latino-am Enfermagem 2003 setembro-outubro; 11(5):593-600.

Trata-se de estudo qualitativo utilizando o método de história de vida, tendo como objeto o cotidiano das mulheresmães-trabalhadoras de enfermagem. Os objetivos foram: descrever o dia-a-dia dessas profissionais, identificar a interferência da profissão na vida dessa mulher e analisar a percepção dessa realidade tomando como base sua história de vida. $A$ análise parcial dos dados revelou que a profissão interfere na vida da mulher, especialmente pelo tipo de atividade que realiza e, em muitas situações, provoca mudança significativa na rotina familiar. A dupla jornada, vivenciada pela grande maioria, foi apontada como uma das causas de cansaço e estresse. Pode-se concluir que, embora a mulher valorize a atividade profissional, se sente sobrecarregada com o acúmulo de funções, relevando a participação do marido compartilhando o dia-a-dia em família.

DESCRITORES: mulheres; trabalho feminino; enfermagem

\section{WOMAN AND WORK - THE HISTORY OF LIFE OF NURSING PROFESSIONALS WHO ARE ALSO MOTHERS}

This study focused on the life of women who are both mothers and nursing professionals, applying the method of life history. The goals were: to describe the every day life of these professionals; to identify the influence of the profession on these women and to analyze the perception of this reality based on their history of life. Data partial analysis showed that the profession interferes in women's lives, considering their type of activity, and that quite often it changes deeply the family's daily routine. Women pointed out that their extremely hard working days cause tiredness and stress. Authors concluded that although women value their career, they are overburdened with the amount of functions, pointing out the importance of the husbands' role sharing the family daily routine.

DESCRIPTORS: women; women's work; nursing

\section{MUJER Y TRABAJO - LA HISTORIA DE VIDA DE MADRES TRABAJ ADORAS EN ENFERMERÍA}

Se trata de un estudio cualitativo utilizando el método historia de vida, teniendo como objeto la cotidianidad de las mujeres-madres-trabajadoras en enfermería. Los objetivos fueron: describir el día a día de estas profesionales; identificar la interferencia de la profesión en la vida de esta mujer y analizar la percepción de esta realidad tomando como base su historia de vida. El análisis parcial de los datos reveló que la profesión interfiere en la vida de la mujer, especialmente por el tipo de actividad que realiza $y$, en muchas situaciones, provoca un cambio significativo en la rutina familiar. La doble jornada, vivida por la gran mayoría, fue señalada como una de las causas de cansancio y estrés. Puede concluirse que aunque la mujer valorice la actividad profesional, se siente sobrecargada con la acumulación de funciones resaltando la participación del marido en el día a día en familia.

DESCRIPTORES: mujeres; trabajo de mujeres; enfermería

\footnotetext{
${ }^{1}$ Doutor em Enfermagem pela Escola de Enfermagem Anna Nery da Universidade Federal do Rio de Janeiro, Professor Adjunto da Faculdade de Enfermagem da Universidade do Estado do Rio de Janeiro, Enfermeira do HUGG da Universidade do Rio de Janeiro, e-mail: spindola@centroin.com.br; ${ }^{2}$ Doutor em Enfermagem, Professor Titular, Coordenador dos Cursos de Pós-Graduação e Pesquisa da Escola de Enfermagem Anna Nery da Universidade Federal do Rio de Janeiro
} 


\section{CONSIDERAÇÕES INICIAIS}

$\boldsymbol{A}$ maternidade (desejada), geralmente, é considerada como ocasião especial na vida da mulher. Se essa é, também, uma profissional, assumindo atividades remuneradas fora do espaço doméstico, esse momento, entretanto, assume outras conotações e os diversos papéis por ela assumidos entram em conflito, obrigando-a a conciliá-los. A partir daí, surgem dúvidas e questionamentos. Compreender como é o dia-a-dia das mulheres-mães-trabalhadoras de enfermagem é, portanto, o objeto deste estudo.

A separação da mãe e seu bebê com o retorno ao trabalho é, sem dúvida, ocasião crucial para todas ${ }^{(1)}$ que precisam encontrar uma forma de conciliar o papel de mãe e profissional. Essa conciliação é difícil não só emocionalmente como, também, fisicamente.

Em nosso cotidiano como mulher, mãe e profissional vivenciamos essas sensações e, apesar de sermos profissionais de saúde, desenvolvendo atividades voltadas para a manutenção/preservação da saúde da população em geral, percebemos que não dispomos de mecanismos (exceto aqueles legalmente reconhecidos) que garantam a administração de nossa vida pública e privada com a tranqüilidade necessária à manutenção do nosso equilíbrio mental.

Assim, ficamos ansiosas, sentindo-nos duplamente culpadas porque não damos a devida atenção (ou que julgamos ser a mais adequada) à nossa casa $\mathrm{e}$ aos nossos filhos, como também não conseguimos dedicar parcela maior de tempo para o desenvolvimento profissional. Essa é uma ocasião importante e crucial para as mulheres-mães que estão inseridas na vida pública, com atividades profissionais.

A sensação de culpa é um sentimento que está associado ao papel de boa mãe e das responsabilidades maternas para com o concepto. Esse sentimento "encontra forte relação na cultura e no processo de educação e socialização do indivíduo"(2). Estudando trabalhadoras das indústrias do setor coureiro-calçadista e similares de Franca/São Paulo, constatou-se que o conflito permeia as relações da mulher com o trabalho e os deveres com a família, seja pela pouca colaboração dos companheiros ou pela falta de aparatos sociais que garantam a educação e guarda dos filhos no período em que estão no trabalho ${ }^{(2)}$.

Aquelas que possuem mais de um emprego têm seu problema agravado, necessitando conciliar as duas situações empregatícias, além das atividades como Mulher e Mãe. Por outro lado, apesar da enfermagem ser uma profissão essencialmente feminina, as trabalhadoras da área pouco se associam às entidades de classe (como associações e sindicatos), o que torna difícil assegurar os direitos legais (como a existência de creches nos locais de trabalho), ficando à mercê de sua própria sorte.

Assim, instigadas pela trama diária com os múltiplos papéis, já com a sensibilidade aguçada, percebemos que esse momento é compartilhado por outras que vivenciam a mesma problemática, independentemente da categoria profissional à qual pertençam. Todas sentem em seu cotidiano alegria, frustração, decepção e preocupação, em decorrência de suas múltiplas funções.

É fato que a enfermagem, ainda nos dias atuais, permanece como profissão essencialmente feminina, haja vista que o percentual de homens que buscam essa opção profissional é reduzido. Assim sendo, é bem elevado o número das pessoas que vivem essa realidade em seu cotidiano, ou seja, serem mães e profissionais de enfermagem, englobando toda complexidade que tal situação comporta.

A preocupação com essa mulher e sua visão de mundo há muito nos inquieta. É certo que essa realidade perpassa nosso cotidiano há algum tempo, na qualidade de mãe e profissional de enfermagem. Todavia, acreditamos que essa vivência contribuiu para clarificar as idéias que sempre estiveram latentes e nas quais sempre acreditamos, ou seja, o quão especiais são aquelas que conseguem conciliar os dois mundos: 0 público e o privado. E para poder compreender melhor essa trama de suas vidas delimitamos as seguintes questões norteadoras: qual é a percepção da mulher-mãe trabalhadora de enfermagem do seu cotidiano? Como concilia as atividades da vida pública e privada? Como percebe a reação familiar em relação à sua vida pública? Como o trabalho desenvolvido interfere na sua vida privada?

A vida da profissional que se torna mãe assume outra conotação $0^{(1)}$, pois ela "agora tem mais uma - e grande responsabilidade". A chegada do bebê redimensiona o seu modo de viver que agora vivencia uma nova realidade, o que faz com que crie condições para conduzir sua vida e de sua família, adaptando-se e ajustando sua vida à do seu filho. Todavia, essas mudanças interferem diretamente na vida da mulher, pois é necessário que tenha uma infra-estrutura familiar bem organizada para 
que sua vida também o esteja, significando que deverá, primeiramente, decidir com quem ficará o bebê, sendo essa uma decisão a ser partilhada com o pai da criança.

A partir dessa problemática, traçamos como objetivos do presente estudo: descrever o cotidiano da mulher-mãe-trabalhadora de enfermagem, identificar a interferência da profissão na sua vida, analisar a percepção da mulher-mãe-trabalhadora de enfermagem em relação ao seu cotidiano, tomando como base sua história de vida.

\section{REFERÊNCIAS CONCEITUAIS}

A mulher e o trabalho

A diferença entre os sexos sempre existiu e esteve presente desde o início dos tempos. Não apenas no sentido biológico, mas principalmente no social. Nas relações entre homens e mulheres as diferenças existentes são apresentadas "como naturais e inquestionáveis, ao contrário, a análise mais profunda de tais relações revela condições extremamente desiguais de exercício de poder, onde as mulheres vêm ocupando posições subalternas e secundárias"(3).

Estudos sobre a temática estão sendo desenvolvidos há algumas décadas por pesquisadores que buscam compreender a evolução e inserção feminina nas sociedades. Os movimentos feministas intensificaram as discussões sobre a mulher e seus papéis e contribuíram para impulsionar a construção do saber acadêmico sobre o tema.

Com a inserção feminina no mercado de trabalho, mudou o curso da história, numa caminhada longa e árdua. O trabalho foi lenta e tardiamente regulamentado em decorrência da falta de organização das mulheres em sindicatos, de sua tradição de resignação e submissão, da falta de solidariedade e consciência coletiva diante das novas condições.

A participação cada vez maior da mulher no mercado de trabalho, compondo a população economicamente ativa e no emprego assalariado, é uma constante desde os anos $70 \mathrm{em}$ todos os países ocidentais $^{(4)}$. Nota-se crescimento da população feminina no mercado de trabalho no Brasil, desde aquela época, cada vez mais intenso e diversificado, não mostrando nenhuma tendência de retrocesso, apesar das crises econômicas que assolaram o país a partir dos anos 80 , fato comprovado em 1990, quando mais de 22,9 milhões de trabalhadoras constituíam cerca de $40 \%$ do conjunto da força de trabalho brasileira.

Nesse sentido, vale acrescentar que a participação feminina no sistema produtivo é definida pelas condições oferecidas no mercado de trabalho, como também pelas potencialidades da mulher inserir-se nesse espaço $^{(5)}$. Assumem importância nesse contexto as características individuais como condição marital, número de filhos, idade e escolaridade que, entre outros atributos, também determinam e/ou facilitam/dificultam a sua inserção no sistema produtivo.

A inserção feminina no mercado de trabalho provocou alterações significativas em seu cotidiano. Esse processo social adquiriu dimensão estrutural no mundo contemporâneo, sendo, junto ao aparecimento de métodos anticoncepcionais mais seguros, um dos fatores que mais radicalmente contribuíram para a redefinição do lugar social da mulher, com conseqüências decisivas nas relações familiares que, gradativamente, foram modificadas em sua organização, na divisão de tarefas domésticas, na educação dos filhos ${ }^{(6)}$.

As trabalhadoras concentram-se em verdadeiros guetos ocupacionais, em especial no setor terciário da economia e, dentro desse, no ramo do trabalho doméstico que reúne atividades de pouco prestígio social ${ }^{(7)}$. Existe diferenciação desses guetos ocupacionais por classes sociais e escolaridade; a mulher tem estado presente nas atividades de nível médio, especialmente nas administrativas e comércio. O magistério e a enfermagem continuam sendo as maiores opções para aquelas que completam o curso superior ${ }^{(7)}$.

Na opção pelo mundo do trabalho deu-se a busca por carreiras que se aproximassem das características femininas. Assim, "a saída de casa deu-se através de profissões tais como enfermagem e magistério, onde a mulher aparece com funções de cuidado e ensino remetidas ao universo familiar"(8).

A singularidade do trabalho da enfermagem é marcante não somente por caracterizar-se como profissão essencialmente integrada por pessoas do sexo feminino como, também, pela especificidade das ações que desenvolvem no dia-a-dia. As profissionais de enfermagem convivem com a dinâmica das organizações no desenvolvimento de suas atividades e, ao mesmo tempo, gerenciam suas vidas como pessoas, esposas e mães. Vale ressaltar que a profissão sofre diretamente os reflexos 
das modificações do cenário em que se insere. Assim, os avanços tecnológicos, as implementações mais diversificadas repercutem no fazer da enfermagem, bem como as retrações financeiras que acabam, em última instância, comprometendo o cuidado prestado à clientela.

O trabalho de enfermagem hospitalar caracterizase por ser contínuo, com atividades 24 horas, sem descanso, com extensa carga horária semanal, realizado cotidianamente, incluindo os dias de feriado e festas comemorativas $^{(9)}$. O trabalho realizado pela enfermeira nesse ambiente, apesar de necessário, é de pouco reconhecimento social, desvalorizado e invisível aos demais profissionais da área de saúde, inclusive aos olhos da clientela que busca ser atendida.

A assistência de enfermagem nas instituições públicas, em geral, tem sido penalizada com a deficiência dos recursos humanos e materiais que interferem diretamente na qualidade da assistência que vem sendo prestada à população. Esse quadro foi analisado ${ }^{(10)}$, sendo apresentada a realidade dos profissionais de enfermagem nos Hospitais Universitários, retratando o sofrimento dos trabalhadores com as condições de trabalho no seu cotidiano. A deterioração do ambiente de trabalho do profissional de enfermagem tem levado a categoria a uma situação em que a crescente evasão e a alta rotatividade têm promovido aumento do "desgaste físico e mental dos trabalhadores remanescentes, na medida em que as atividades precisam ser redistribuídas entre aqueles que permanecem, sem possibilidades de manutenção da qualidade de assistência prevista"(10).

O sofrimento dos profissionais de enfermagem na realização de suas atividades rotineiras foi analisado em outros estudos $^{(11)}$, verificando-se a correlação entre prazer e sofrimento dos trabalhadores na prestação de assistência nas Instituições de saúde.

\section{METODOLOGIA}

Trata-se de estudo qualitativo utilizando o método de história de vida. A história de vida é um método em que a pessoa relata situações ou fatos que vivenciou/vivencia, sendo valorizado pelo pesquisador a visão que o indivíduo tem sobre aquele assunto. No Brasil, o método foi empregado inicialmente na área de educação ${ }^{(12)}$ e, posteriormente, foi adotado para estudos na área de enfermagem.
Nessa abordagem metodológica o que interessa ao pesquisador "é o ponto de vista do sujeito. O objetivo desse tipo de estudo é justamente apreender e compreender a vida conforme ela é relatada e interpretada pelo próprio ator" ${ }^{\text {(12) }}$. Assim, o método de história de vida ou relato de vida "tem como conseqüência tirar o pesquisador de seu pedestal de "dono do saber" e ouvir o que o sujeito tem a dizer sobre ele mesmo: o que ele acredita que seja importante sobre sua vida"(12).

Sendo assim, "o sujeito não relata simplesmente sua vida, ele reflete sobre ela enquanto conta"(13). Nessa abordagem o pesquisador respeita a opinião dos participantes, e acredita no que diz.

O presente estudo está sendo desenvolvido em um Hospital Geral Público do Município do Rio de Janeiro. A instituição selecionada é o local onde uma das pesquisadoras desenvolve atividades profissionais, o que facilitou a aproximação aos sujeitos do estudo. Foi solicitada autorização à Superintendência de Enfermagem para nos aproximarmos das trabalhadoras de enfermagem e apresentar a proposta do estudo, verificando seu interesse em participar e solicitando sua colaboração. Nesse sentido, foram respeitadas as diretrizes e normas que regulamentam as pesquisas envolvendo seres humanos, estabelecidas pela Resolução 196/96 do Conselho Nacional de Saúde ${ }^{(14)}$.

$\mathrm{Na}$ obtenção dos relatos, aproximamo-nos das depoentes, expondo-lhes nossa proposta de trabalho e deixando-as à vontade para participar. Às mulheres que se interessaram, entregamo-Ihes o Termo de Consentimento e realizamos uma entrevista aberta com a questão: fale-me de sua vida, de seu cotidiano como mulher, mãe e trabalhadora de enfermagem. Utilizamos o recurso de gravação em fita magnética (cassete), mediante prévia aquiescência das depoentes, visando garantir a fidedignidade daquilo que foi dito durante as entrevistas e 0 anonimato.

Realizamos 25 (vinte e cinco) entrevistas. Encerramos a coleta de depoimentos após percebermos que os relatos estavam se tornando repetitivos, tendo atingido o ponto de saturação ${ }^{(13)}$. A análise iniciou-se tão logo começaram as transcrições das fitas, ou seja, imediatamente após as primeiras entrevistas. Os relatos foram lidos e relidos quantas vezes se fizeram necessários para a apreensão das categorias emergentes das falas das entrevistadas. 


\section{ANÁLISE DOS RELATOS}

Realizamos uma pré-análise em 13 entrevistas das quais extraímos as seguintes categorias preliminares: mulher x profissão: - relação trabalho/filho/marido; profissão interferindo vida pessoal; - o ser mulher e trabalhadora - cansaço/estresse.

Uma das categorias que emergiu dos relatos foi a relação com a profissão, ou seja, a relação do trabalho remunerado com o ser mulher: como o trabalho interfere no seu dia-a-dia como mulher e mãe, como fica a relação com o companheiro, os filhos e demais familiares, ou seja, o que modifica para aquelas que são trabalhadoras na área de enfermagem.

Relação trabalho/filho/marido

A relação do trabalho remunerado com a vida familiar está presente nas falas das mulheres, revelando como interfere no seu cotidiano como mulher, esposa e mãe. Principalmente pelo tipo de atividade que realizam, o trabalho de enfermagem, que ocorre nas instituições hospitalares, em horários diversificados (manhã, tarde, noite, regime de plantão diurno e noturno) e acaba por intervir na rotina das famílias. Os relatos que se seguem esclarecem esse pensar: (...) elas não tiveram nenhum problema no colégio, assim pela ausência da mãe (...) porque o meu marido ele é muito participativo com relação às meninas (...) ele divide as atividades comigo (...) então tem que ter esta participação (...) o marido precisa estar envolvido também, para as coisas darem certo (...) mas tem que ter o companheirismo. Até no nosso relacionamento fica uma coisa melhor (...) (Beth, 36 anos, casada, 02 filhos, Aux. Enfermagem).

(....) a gente como mulher é uma coisa, (...) mulher profissional e esposa é outra, mulher, profissional, esposa e mãe é outra bem diferente, a gente vai ganhando mais atribuições, (...) eu divido todas as coisas com meu esposo, (...) Eu cuido da casa, eu cuido das crianças, mas existe uma parceria (...) (Alcina, 35 anos, casada, 02 filhos, Enfermeira).

Nos relatos anteriores, podemos perceber a relação das profissionais com o trabalho de enfermagem e a importância da participação do marido na rotina doméstica. Alcina e Beth exteriorizam que a participação de seus companheiros é fundamental para a conciliação de suas atividades domésticas e laborais, auxiliando-as no cuidado com os filhos, nas atividades com a casa, denotando a necessidade do novo perfil dos homens atuais (participar do dia-a-dia em família, dividir tarefas).

Esse aspecto é reforçado por estudiosos ${ }^{(6)}$, afirmando que, com a inserção feminina no mercado de trabalho, a configuração familiar sofreu modificações na sua organização, divisão de tarefas domésticas e educação dos filhos. Assim sendo, além da participação masculina (quando existe) a mulher lançou mão de aparatos sociais, como as creches, e equipamentos para auxiliar na rotina doméstica (máquinas de lavar roupa e louças, alimentos congelados, freezer e outros), o que alterou o modelo familiar tradicional.

É relatado, também, a dificuldade da mãe em conciliar as atividades profissionais quando os filhos são pequenos, em função da separação da criança por acreditar que sua presença é fundamental para seu desenvolvimento, embora, como Alcina (35 anos, casada, 02 filhos, Enfermeira) destaque que, muitas vezes, sua presença possa prejudicar a criança com tanta atenção:

... a volta ao trabalho depois do primeiro filho (...) a dificuldade maior era para eu deixá-lo e vir trabalhar (...) a gente acha que só nós sabemos dar a assistência adequada (risos) aí depois a gente vê que nós até estragamos com assistência demais.

As mães trabalhadoras têm consciência do seu papel no acompanhamento de seus filhos, principalmente se são menores, embora reconheçam, também, que é um período passageiro, uma fase difícil pela qual passa a maioria das mulheres que trabalham remuneradamente, independente da categoria profissional a qual pertençam.

Em relação à maternidade, é citado por estudiosos do assunto(1) $^{(1)}$, com a chegada do bebê, a mãe tem uma nova e grande responsabilidade e necessita de uma infra-estrutura familiar para reassumir sua vida profissional. Outro ponto abordado pelas profissionais é a questão da falta de tempo para conciliar as diversas atividades do dia-a-dia, como veremos no relato a seguir: (...) Eu tenho que ver o que está faltando e o que não está faltando, e os finais de semana eu ainda tenho que me virar em mercado, mulher, mãe e ainda ter aquela paciência (...)Temos que trabalhar. (...) Tenho que ser mãe e pai. (...) minha mãe também fica assim: você não dá mais atenção para nós, (...) você trabalha tanto, é uma fuga? Só que não entende que eu tenho gastos porque eu tenho que pagar colégio, tudo ,(...) A não ser que (...) eu paro tudo e vou ser mãe. Porque, às vezes, fica muito difícil conciliar ser mãe, mulher e profissional (...) (Larissa,34 anos, casada, 02 filhos, Enfermeira).

O dia-a-dia do trabalho com as dificuldades inerentes às atividades de enfermagem é exteriorizado, ficando evidente sua vida como mãe, mulher e dona-decasa. No caso específico, essa trabalhadora tem 2 filhos 
de casamentos anteriores e, embora tenha um companheiro, assume por razões financeiras maior carga laboral, sentindo diretamente o peso de sua responsabilidade. As atividades remuneradas não a desvinculam de suas tarefas domésticas, do cuidado com os seus. A preocupação com os filhos é uma constante em seu cotidiano, seja pela falta de acompanhamento mais amiúde de sua rotina, ou pela cobrança que esses fazem de sua ausência em casa. Assim, embora valorize o trabalho remunerado, como forma de manter sua independência, ainda permanece arraigado, como parte de suas funções, acompanhar o desenvolvimento de sua prole, sendo responsável por essa assistência mesmo que à distância.

A família moderna mudou o seu perfil ${ }^{(15)}$. As mães estão cada vez mais isoladas de outro parente, assumindo o cuidado de sua prole, mesmo que exerça atividade remunerada. Elas maternam e, não apenas geram, assumindo a responsabilidade pelo cuidado das crianças. Esse aspecto do perfil feminino, observado mais intensamente a partir do século XVIII, é relacionado ao papel da boa mãe no cuidado de seus filhos. É bem verdade que, atualmente, em função da necessidade de trabalharem remuneradamente, surgiu um novo perfil de homem mais participativo, dividindo tarefas domésticas, todavia, são casos isolados, não sendo uma constante em todos as famílias.

Profissão interferindo na vida pessoal

As entrevistadas em seus relatos referiram que o dia-adia no trabalho remunerado, muitas vezes, interfere na rotina familiar, como esposa e mãe, em decorrência do exercício profissional na área de enfermagem: (...) Na verdade, é isso, a enfermagem comeu a metade da minha vida,(...) porque você tenta compensar o lado material, fazer plantão para os outros e outro emprego e acaba deixando o lado afetivo de mãe e mulher, deixando do lado de fora (...) enfermagem é difícil conciliar porque a gente não tem dia nem hora. Se você está de plantão, está de plantão e pronto acabou, é dia santo, festa, não tem nada (...) E acaba você perdendo festas de família, Natal, Ano Novo, (...) e você, às vezes, perde doze horas lá fora que quando você vai ver já aconteceu, você perdeu (...) (Valéria, 41 anos, casada, 02 filhos, Aux. Enfermagem).

(...) De repente, em um mês eu perdi o meu marido e fiquei à frente (...) depois fiz o curso de auxiliar de enfermagem. (...) esta profissão os horários são muito complicados (...) eu fico muito pouco com eles e eu acho que comigo e com a maioria das mulheres isso é muito sofrido porque a gente tem aquela sensação de que não está cumprindo o papel essencial que é o papel de mãe e eu acho que toda mulher tem que ter o seu profissional, mas basicamente a gente é criada para ser mãe (...) (Marina, viúva, 47 anos, 04 filhos, Aux. Enfermagem).

Os relatos anteriores deixam transparecer que as entrevistadas sentem-se divididas em seu dia-a-dia como trabalhadoras e mães. As atividades profissionais na área de enfermagem freqüentemente comprometem a rotina familiar, provocando-lhes sensação de perda ou frustração. A profissão, com sua dinâmica de trabalho em turnos (de oito a doze horas cada), limita a vida das trabalhadoras que necessitam organizar-se conforme sua carga horária. Para Marina, interfere diretamente no relacionamento com os filhos, em função da ausência de casa, acarretando grande sofrimento, enquanto que Valéria afirma enfaticamente a enfermagem comeu metade da minha vida.

As profissionais sentem-se, na maioria das vezes, muito divididas entre o mundo público e o privado. Algumas até exteriorizam que mulheres que têm filhos pequenos não deveriam trabalhar fora...é melhor deixá-los crescer primeiro. Nesse sentido, é importante ressaltar que as trabalhadoras de enfermagem, comparadas às demais que mantêm atividades remuneradas, têm características peculiares como: o tipo de trabalho, o regime de plantão, a qualidade do serviço, dentre outros, que as diferenciam e, portanto, apresentam condição distinta, merecendo atenção especial.

A responsabilidade com a guarda, o cuidado e a educação das crianças, na grande maioria das famílias, é exclusivamente delas, caso a remuneração não compense os gastos com a sua saída de casa, ela acaba por abandonar o trabalho remunerado. Por outro lado, também, se a atividade remunerada não puder ser conciliada com a rotina familiar acabará gerando desencontros, desentendimentos e, por vezes, até o abandono do trabalho(4).

O ser mulher e trabalhadora - cansaço e estresse

Estar inserida no mercado de trabalho é, também, encontrar-se com cansaço e estresse como exteriorizam em seus relatos as profissionais de enfermagem. A atividade remunerada, na verdade, não as desvincula da responsabilidade com a casa e os filhos. Em algumas situações essas são partilhadas com os companheiros, todavia, esse quadro não é uma constante para todas 
as mulheres como veremos a seguir: (...) a mulher trabalha muito mais porque nós trabalhamos fora, chegamos em casa sempre tem alguma coisa para fazer, (...) eu sei que tem marido que ajuda muito também, mas, de um modo geral, a sobrecarga maior é sempre em cima da gente, (...) além do trabalho, (...) tem que ver o que a empregada fez, se fez direito, ou pensar no que tem que fazer amanhã, (...) tem uma sobrecarga muito maior que os maridos (...) sofre mais por causa dos filhos (...) Se é médico a gente que leva, (...) acaba trabalhando muito mais, fica muito mais estressada do que os maridos (...) eu acho que (...) trabalhar fora e ser mãe é uma coisa muito complicada (...) (Thaís, casada, 38 anos, 01 filho, Aux. Enfermagem).

(...) normalmente é assim, você se desgasta com o filho e quando chega no marido (...) é pior ainda, então o cansaço é muito maior, é todo um desgaste, (...) a gente se deixa levar muito pelo trabalho, (...) e o desgaste é muito grande, às vezes a gente não aproveita realmente o que (...) deveria aproveitar, (...) eu estou (...) meio abalada com toda essa situação de ter trabalhado muito, (...) de muito estresse de trabalho, você se desgasta no trabalho (...) quando você tem um emprego só você ainda consegue, (...) é difícil (...) (Marlene, casada, 35 anos, 02 filhos, Enfermeira).

Esses relatos deixam transparecer que a associação trabalho remunerado e atividades rotineiras da casa são revestidos de cansaço e estresse. Na verdade, a trabalhadora acumula funções e sente o peso dessa responsabilidade. O dia-a-dia com a família, as atividades profissionais, seus interesses pessoais, enfim, um somatório de atribuições realizadas, na maioria das situações, de maneira isolada, sem compartilhar, o que contribui, muitas vezes, para o seu desgaste. É fato que a configuração dos tempos atuais é distinta da época em que não exerciam atividades fora do lar, hoje necessita ter um rendimento para reforçar a renda familiar. Assim, a participação na força de trabalho gera nova desigualdade que é a dupla jornada, no público e no lar ${ }^{(2)}$. Nesse sentido, vale acrescentar que a mulher ao assumir a vida pública não se desvinculou das atividades que exercia na vida privada e, assim, seu cotidiano foi modificado, entendendo o cotidiano como um conjunto de situações vivenciadas pelas pessoas, percebidas de maneira individual e renovando-se a cada instante.

A mulher, em nossa sociedade, apesar dos avanços tecnológicos já alcançados, ainda tem arraigadas em seu inconsciente as obrigações domésticas, conseguindo partilhar muito pouco de suas atividades com o companheiro. Ao exercer a enfermagem, trabalhando diretamente com o ser humano, num contexto histórico de dedicação, seriedade e responsabilidade no qual a profissão é vista como um sacerdócio, sente mais diretamente o peso que sua ausência acarreta no trabalho. Assim, assume as diversas atividades que se apresentam no seu dia-a-dia, o que contribui para a sobrecarga de trabalho, a qual, em muitas situações, ocasiona o estresse e/ou distúrbios no organismo.

\section{CONSIDERAÇÕES FINAIS}

A realização deste estudo permitiu-nos compreender melhor como é o dia-a-dia das profissionais de enfermagem que convivem com a realidade de exercer uma atividade remunerada e ser mãe. A complexidade dessas ações pode ser percebida em seus relatos que denotam a sensibilidade aguçada dessas pessoas.

O trabalho remunerado assume papel importante nos seus relatos. Ao longo dos anos, foi-se percebendo que a figura da mulher prendada, dona-de-casa, havia cedido lugar, também, à trabalhadora e que passou a ocupar os dois espaços.

O ser mulher foi pouco exteriorizado nas suas falas. Em algumas entrevistas questionamos sobre esse aspecto, sendo revelado que estava esquecida, ou seja, com os diversos papéis por elas assumidos, deixam-se ficar em segundo plano. A multiplicidade de papéis e as exigências dos mesmos na vida de cada uma delas interfere de maneira significativa no seu dia-a-dia, pois, ao priorizar um ou outro acaba esquecendo-se do Ser Mulher.

Há um certo tempo, de maneira geral, costumavam se dedicar a seus familiares, abrindo mão de sua própria satisfação em prol dos filhos e companheiros. A inserção no mercado de trabalho alterou esse quadro. Conciliar a atividade remunerada com o cotidiano familiar nem sempre é uma tarefa das mais simples, todavia, as trabalhadoras de enfermagem, cada uma com sua história de vida, têm buscado o alcance da realização pessoal. Cada vez mais a mulher está inserida no mercado de trabalho, conquistando espaços, delimitando novos horizontes nesse universo de possibilidades, apesar dos percalços do caminhar. 


\section{REFERÊNCIAS BIBLIOGRÁFICAS}

1. Glat R. Ser mãe e a vida continua... $2^{a}$ ed. Rio de Janeiro (RJ): Agir; 1994.

2. Bueno CMLB. A mulher e a culpa - relações entre o trabalho e a maternidade: um estudo realizado com as trabalhadoras das indústrias do setor coureiro-calçadista e similares de Franca. [dissertação]. São Paulo (SP): Faculdade de História, Direito e Serviço Social da Universidade Estadual Paulista; 1998.

3. Fonseca RMGS. Espaço e gênero na compreensão do processo saúde doença da mulher brasileira. Rev Latinoam Enfermagem 1997 janeiro; 5(1):5-13.

4. Schirmer J. Trabalho e maternidade: qual o custo para as mulheres? In: Bretas ACP. Trabalho, saúde e gênero: na era da globalização. Goiânia (GO): AB; 1997. p.101-13.

5. Bruschini C. Mulher e Trabalho: a brasileira conquista novos espaços. Mercado Global 1992 3ำtrim.; 87:52-8.

6. Sarti CA. Os filhos dos trabalhadores: quem cuida das crianças? In: Bretas ACP. Trabalho, saúde e gênero: na era da globalização. Goiânia (GO): AB; 1997. p. 51-60.

7. Fonseca RMGS. Atenção: Mulheres Trabalhando! (na vida, na saúde, na enfermagem). In: Fonseca RMGS, organizadora. Mulher e cidadania na nova ordem social. São Paulo: NEMGE/ USP; 1996. p. 97-110.

8. Moreira MCN. Imagens no espelho de Vênus: mulher, enfermagem e modernidade. Rev Latino-am Enfermagem 1999 janeiro; 7(1):55-65.

9. Suazo SVV. Trabajo de enfermería: Un trabajo penoso? Chile, 2000. Prelo da Revista Rede Feminista.

10. Lunardi WD Filho. Prazer e sofrimento no trabalho: contribuições à organização do processo de trabalho da enfermagem. [dissertação]. Rio Grande do Sul (RS): Faculdade de Ciências Econômicas da Universidade do Rio Grande do Sul; 1995.

11. Beck CLC. O sofrimento do trabalhador - da banalização a re-significação ética na organização da enfermagem. Florianópolis (SC): UFSC; 2001.

12. Glat R. Somos iguais a vocês: depoimentos de mulheres com deficiência mental. Rio de Janeiro (RJ): Agir; 1989.

13. Bertaux D. L'approche biographique: sa valité méthodologique, ses potentialités. Cahiers internationaux de sociologie 1980; 69:197-225.

14. Ministério da Saúde (BR). Fundação Oswaldo Cruz. Diretrizes e normas regulamentadoras de pesquisas envolvendo seres humanos. Resolução 196/96 do Conselho Nacional de Saúde. Brasília (DF): MS/FIOCRUZ; 1996.

15. Chodorow N. A psicanálise da maternidade: uma crítica a Freud a partir da mulher. Rio de Janeiro (RJ): Rosa dos Tempos; 1990. 